Article

\title{
Evaluation of the Miscibility of Novel Cocoa Butter Equivalents by Raman Mapping and Multivariate Curve Resolution-Alternating Least Squares
}

\author{
Efraín M. Castro-Alayo ${ }^{1,2,3, *(\mathbb{D})}$, Llisela Torrejón-Valqui ${ }^{1}$, Ilse S. Cayo-Colca ${ }^{4}(\mathbb{D})$ and Fiorella P. Cárdenas-Toro ${ }^{2,3}$ \\ 1 Facultad de Ingeniería y Ciencias Agrarias, Instituto de Investigación, Innovación y Desarrollo para el Sector \\ Agrario y Agroindustrial de la Región Amazonas (IIDAA), Universidad Nacional Toribio Rodríguez de \\ Mendoza de Amazonas, Calle Higos Urco 342-350-356, Chachapoyas 01001, Peru; \\ llisela.torrejon@untrm.edu.pe \\ 2 Sección de Ingeniería Industrial, Departamento de Ingeniería, Pontificia Universidad Católica del Perú, \\ Av. Universitaria 1801, San Miguel 15088, Peru; fcardenas@pucp.pe \\ 3 Programa de Doctorado en Ingeniería, Departamento de Ingeniería, Pontificia Universidad Católica del Perú, \\ Av. Universitaria 1801, San Miguel 15088, Peru \\ 4 Facultad de Ingeniería Zootecnista, Agronegocios y Biotecnología, Universidad Nacional Toribio Rodríguez \\ de Mendoza de Amazonas, Calle Higos Urco 342-350-356, Chachapoyas 01001, Peru; \\ icayo.fizab@untrm.edu.pe \\ * Correspondence: efrain.castro@untrm.edu.pe; Tel.: +51-98-637-6463
}

check for updates

Citation: Castro-Alayo, E.M.; Torrejón-Valqui, L.; Cayo-Colca, I.S.; Cárdenas-Toro, F.P. Evaluation of the Miscibility of Novel Cocoa Butter Equivalents by Raman Mapping and Multivariate Curve ResolutionAlternating Least Squares. Foods 2021, 10, 3101. https://doi.org/10.3390/ foods10123101

Academic Editor: Lili He

Received: 10 November 2021 Accepted: 10 December 2021 Published: 14 December 202

Publisher's Note: MDPI stays neutral with regard to jurisdictional claims in published maps and institutional affiliations.

Copyright: (c) 2021 by the authors. Licensee MDPI, Basel, Switzerland. This article is an open access article distributed under the terms and conditions of the Creative Commons Attribution (CC BY) license (https:// creativecommons.org/licenses/by/ $4.0 /$ )
Abstract: Cocoa butter (CB) is an ingredient traditionally used in the manufacturing of chocolates, but its availability is decreasing due to its scarcity and high cost. For this reason, other vegetable oils, known as cocoa butter equivalents (CBE), are used to replace CB partially or wholly. In the present work, two Peruvian vegetable oils, coconut oil (CNO) and sacha inchi oil (SIO), are proposed as novel CBEs. Confocal Raman microscopy (CRM) was used for the chemical differentiation and polymorphism of these oils with CB based on their Raman spectra. To analyze their miscibility, two types of blends were prepared: $\mathrm{CB}$ with $\mathrm{CNO}$, and $\mathrm{CB}$ with SIO. Both were prepared at 5 different concentrations (5\%, 15\%, 25\%, 35\%, and 45\%). Raman mapping was used to obtain the chemical maps of the blends and analyze their miscibility through distribution maps, histograms and relative standard deviation (RSD). These values were obtained with multivariate curve resolution-alternating least squares. The results show that both vegetable oils are miscible with $\mathrm{CB}$ at high concentrations: $45 \%$ for $\mathrm{CNO}$ and $35 \%$ for SIO. At low concentrations, their miscibility decreases. This shows that it is possible to consider these vegetable oils as novel CBEs in the manufacturing of chocolates.

Keywords: cocoa butter; coconut oil; sacha inchi oil; confocal raman microscopy; raman mapping; multivariate curve resolution-alternating least squares; chocolate

\section{Introduction}

In the manufacture of chocolates, one of the main ingredients is cocoa butter (CB), which is the main contributor to the high fat content of chocolate. In total, 30 to $40 \%$ of the weight of chocolate is fat [1]. CB remains as a solid at $20{ }^{\circ} \mathrm{C}$ (with hard texture and snap) and melts rapidly at $33^{\circ} \mathrm{C}$, leading to the release of flavor and soft mouth-feel texture [2,3]. Cost and technical limitations have increased CB demand, although it is the main lipid phase in chocolate manufacturing. In addition, it is also used in combination with other vegetable oils, such as hydrogenated or partially hydrogenated soybean oil and palm oil [2-4]. Therefore, researchers have been searching for cheaper alternatives with similar characteristics to CB [2]. These alternatives should improve the physical properties and bloom resistance and reduce the health risks of the final product [3]. $\mathrm{CB}$ can be substituted with vegetable fats by blending to produce chocolate or replace $\mathrm{CB}$ either partially or wholly [2]. These are the so-called cocoa butter equivalents (CBE), which 
should be compatible with $\mathrm{CB}$ without presenting any eutectic behavior [5]. According to Norazlina et al. [2], CBEs are nonlauric fats that are obtained from the fractionation, interesterification and blending of fats and oils. CBEs have physicochemical, thermal and sensory attributes similar and compatible with those of $\mathrm{CB}$, so they can be miscible in any proportion without changing the characteristics of $\mathrm{CB}$ (that is, they are fully compatible with CB properties) [2,6-8]. CBEs also possess TAGs similar to those in CB but are produced from low-cost vegetable oils [9]. Some countries allow the use of noncocoa vegetable fats or oils at a defined maximum level to improve the properties of chocolate [10]. The current legislation of the European Union allows the incorporation of up to 5\% of CBE in the total weight of the chocolate [11], while the United States legislation does not specify this value [12-14]. European regulation only allows six vegetable oils to be used as CBE, specifically illipe, palm oil, sal, shea, kokum gurgi and mango kernel [11,13].

In the Peruvian amazon, sacha inchi (Plukenetia huayabambana L.) is cultivated. This plant is known as the Inca peanut and is an important source of phenolic compounds and high antioxidant capacity $[15,16]$. Sacha inchi oil (SIO) is emerging as a functional food due to its rich composition of polyunsaturated fatty acids, tocopherol and sterols. These compounds have shown multiple human health benefits [17]. Coconut oil (CNO) is used in food manufacturing. It is a saturated fat rich in small and medium chain fatty acids, comparable to animal fat [18]. The scientific and nonspecialized literature promotes the consumption of $\mathrm{CNO}$ based on the assumption that it is beneficial for health because it is low in cholesterol, reduces the risk of cardiovascular diseases, encourages weight loss, and improves cognitive functions, among others [19]. In Peru, these natural vegetable oils are produced, and could be good candidates to be considered novel CBEs.

During food manufacturing, some ingredients, even when they may be macroscopically miscible, can show microscopic heterogeneities that would cause instability and phase separation during storage [20]. This is a problem in the manufacture of pharmaceutical tablets, but is also a problem in the manufacture of chocolates. To ensure the quality of the final product, analytical techniques are used to create chemical maps [21] and determinate their miscibility. Some researchers are developing methodologies based on Raman mapping (or Raman imaging) for the evaluation of miscibility between ingredients [20,22-24]. Raman spectroscopy can offer widespread food safety assessments in a nondestructive, easy to operate, sensitive, and rapid manner [25]. Raman mapping assimilates two important technologies, imaging and Raman spectroscopy, to simultaneously provide an image of, and spectral information regarding, food products [26]. The purpose of Raman mapping is to visualize the distribution of components by chemical properties in a sample [25] and to study heterogeneous materials, since it provides submicron spatial resolution with high sensitivity [27].

In Raman mapping, each pixel in the image corresponds to a Raman spectrum, which is compared to an established Raman database to determine the specific analytes or spectral background measurements in this location [25]. The spectral information obtained is complex, so multivariate analysis is necessary to unravel complex spectral data from Raman mapping data [21]. Multivariate curve resolution-alternating least squares (MCRALS) is a self-modeling curve resolution method that offers the possibility of extracting physically meaningful spectra associated with pure components from the mixed Raman spectra of real biological samples with the benefit of not requiring prior information about the nature of the sample [28]. Using MCR-ALS, Mitsutake et al. [22] found that CB and CNO present intermediate miscibility at concentrations of $75 \%$ and $25 \%$, respectively, when used in the manufacture of pharmaceutical tablets.

Raman mapping is expected to be a useful tool for the food industry to assess the quality and safety of food [26]; however, there is scarce information on this topic. The present work focuses on two important approaches for the food industry: the search for natural sources of Peruvian origin for use in the chocolate industry as novel CBEs, and the use of a new non-destructive analysis technique to evaluate the miscibility of these natural sources with $\mathrm{CB}$ as a first step for the development of new CBEs. Thus, the objective of this 
work was to study the miscibility of CNO, SIO, and CB using confocal Raman microscopy and MCR-ALS to propose novel CBEs for the chocolate industry.

\section{Materials and Methods}

\subsection{Materials}

The vegetable oils used were pure $\mathrm{CNO}$ and SIO, which were purchased from a local market in Chachapoyas, Peru. CB was provided by the Cooperativa de Servicios Múltiples Aprocam (Bagua, Amazonas, Peru).

\subsection{Sample Preparation}

Following Mitsutake et al. [22], the samples were prepared by heating them to $10{ }^{\circ} \mathrm{C}$ above the $\mathrm{CB}$ melting point; the materials were added while stirring until a visually homogeneous blend was obtained. Two batches were prepared: the first was composed of $\mathrm{CB}$ and $\mathrm{CNO}$ (CB-CNO), and the second was composed of CB and SIO (CB-SIO). Each batch contained 5 concentrations of vegetable oils, ranging from $5 \%$ to $45 \%$ (Table 1), and 3 replicates of each concentration were produced. The samples were placed in a chocolate mold and cooled to $4{ }^{\circ} \mathrm{C}$ for easy removal of the tablets. A piece of $1 \times 1 \mathrm{~cm}^{2}$ was removed from each tablet for Raman mapping.

Table 1. Composition of the samples.

\begin{tabular}{cccc}
\hline Sample & Cocoa Butter (\%) & Coconut Oil (\%) & Sacha Inchi Oil (\%) \\
\hline CB55-CNO45 & 55 & 45 & - \\
CB65-CNO35 & 65 & 35 & - \\
CB75-CNO25 & 75 & 25 & - \\
CB85-CNO15 & 85 & 15 & - \\
CB95-CNO05 & 95 & 05 & 45 \\
CB55-SIO45 & 55 & - & 35 \\
CB65-SIO35 & 65 & - & 25 \\
CB75-SIO25 & 75 & - & 15 \\
CB85-SIO15 & 85 & - & 05 \\
CB95-SIO05 & 95 & & \\
\hline
\end{tabular}

\subsection{Raman Mapping}

Following the process of Mitsutake et al. [22] with some modifications, the samples were mapped using a Raman confocal microscope system (Horiba Scientific, XploRA plus, Montpellier, France). Chemical maps were obtained by a $532 \mathrm{~nm}$ laser as an excitation light with a 50\% filter. The experimental conditions were as follows: $100 \mathrm{~nm}$ slit width, pinhole $100 \mu \mathrm{m}, x 50 / 0.90 \mathrm{NA}$ Vis-LWD air objective, and $1 \mathrm{~s}$ acquisition time with 2 accumulations. The Raman signal was obtained using a 600 lines/mm grating centered between 800 and $3100 \mathrm{~cm}^{-1}$. The acquired spectra were corrected in a range from 1000 to $1800 \mathrm{~cm}^{-1}$, smoothed, and baseline corrected using LabSpec 6 Suite software. Each sample generated a cube of data with dimensions of $25 \times 25 \times 761$, where 25 was the number of pixels at the $x$ and $y$ axes and 761 was the number of spectral variables.

\subsection{Data Analysis of Chemical Maps}

According to Vajna et al. [29], before chemometric evaluation, all spectra were baseline corrected (this was done by using the same baseline points for all maps and pure component spectra). Then, the spectral range from 1000 to $1800 \mathrm{~cm}^{-1}$ was used for the corresponding evaluation. Raman chemical map data were analyzed by using Solo+MIA software (Eigenvector, Research, Inc. Wenatchee, WA, USA). The raw 3-dimensional data were unfolded into a 2-dimensional matrix. The estimation of pure component spectra from the Raman chemical maps was carried out by MCR-ALS. This technique is based on the following bilinear model (Equation (1)):

$$
X=C S^{T}+E
$$


where $X(p * \lambda)$ is the matrix containing the mapping spectra, $S^{T}(k * \lambda)$ is the set of pure component spectra, and $C(p * k)$ contains the vectors of spectral concentrations (each row in $C$ contains the concentrations of the $k$ ingredients). The matrix $E$ represents the residual noise. MCR-ALS generated both the concentration matrix $C$ (scores) and recovered spectrum matrix $S^{T}$ (loadings) from the dataset $X$ in an iterative manner, using an initial estimation for either $C$ or $S^{T}$ and appropriate constraints.

\section{Preprocessing and Constraints}

The preprocessing technique was normalized (1-norm, area $=1$ ). The normalization of concentration profiles or resolved spectra or use of reference concentration values within the optimization helps to suppress the rotational ambiguity [30]. The applied constraints were non-negativity, which forces the profiles to be formed by positive values and can be implemented replacing negative values by zeros [30], and equality, which makes the concentration profile and/or spectra of a component equal to a certain known predefined shape [30]. Pure CB, CNO, and SIO spectra were used as equality constraints.

\subsection{Miscibility}

To determinate the miscibility of the vegetable oils proposed as novel CBEs with $\mathrm{CB}$, the homogeneity of the samples was quantitatively and qualitatively determined. The relative standard deviation (RSD) is a commonly used tool in the pharmaceutical industry to estimate the homogeneity of a component within a blend [31] and describe the distribution of the components quantitatively. The RSD was calculated from the ratio of the standard deviation $(\sigma)$ and the mean $(\mu)$ of each measured image score. Using RMarkdown software, the RSD of the scores within a chemical image was calculated. A lower RSD of the chemical image corresponded to a more homogeneous distribution of the respective ingredient $[29,32,33]$ and, therefore, its miscibility. Qualitatively, the homogeneity of the samples was analyzed using histograms. According to Gendrin et al. [33], a histogram showing a symmetric distribution with a narrow base and sharp peak is representative of a low-contrast image and therefore of a homogeneous sample. Conversely, an asymmetric histogram with a wide base and flatter peak or several modes is representative of a more contrasted image, i.e., a heterogeneous sample.

\section{Results}

\subsection{Characterization of the Spectra of Cocoa Butter and Vegetable Oils}

Figure 1 shows the characteristics of the Raman spectra of the pure components (CB, $\mathrm{CNO}$, and SIO) in the full range $\left(1000-3100 \mathrm{~cm}^{-1}\right)$ at room temperature $\left(20^{\circ} \mathrm{C}\right)$. In the CB spectra, the $\mathrm{C}-\mathrm{H}$ stretching region shows peaks at 2885.7 and $2886.1 \mathrm{~cm}^{-1}$ which are assigned to alkyl-chain methylene symmetric $\left(v_{\mathrm{s}}\right)$ and antisymmetric $\left(v_{\mathrm{as}}\right)$ stretching. A peak at $2936.5 \mathrm{~cm}^{-1}$ associated with the terminal methyl $v_{\mathrm{s}}\left(\mathrm{CH}_{3}\right)$ stretch was observed. In the $\mathrm{C}=\mathrm{O}$ stretching region, we can see 2 peaks at 1745.4 and $1733.8 \mathrm{~cm}^{-1}$, which are representative of forms III and IV at room temperature (Figure 2). The full width at half maximum (FWHM) of the peak at $1745.4 \mathrm{~cm}^{-1}$ was $17.38 \mathrm{~cm}^{-1}$. In the $\mathrm{C}=\mathrm{C}$ stretching region $\left[v_{s}(C=C)\right]$ of the olefinic band, we can see a peak at $1662.7 \mathrm{~cm}^{-1}$ (Table 2), representing the solid state of CB form IV at room temperature. This peak is of greater intensity in SIO due to its liquid state and is also related to the proportion of oleic acid. A total of 2 peaks at 1445.9 and $1462.9 \mathrm{~cm}^{-1}$ in the $\mathrm{CH}_{2}$ and $\mathrm{CH}_{3}$ deformation regions can also be seen. In the $\mathrm{CH}_{2}$ twisting region, we can also see a peak at $1301.3 \mathrm{~cm}^{-1}$, which is related to the degree of coupling of the alkyl chains in the lipids. The CB spectra also reveal 3 characteristic peaks of the CB polyforms, located in the $C-C$ stretching range $\left(1030-1183 \mathrm{~cm}^{-1}\right)$. The peak at $1102.21 \mathrm{~cm}^{-1}$ indicates the existence of $\mathrm{CB}$ in its solid state at room temperature. This peak is not present in $\mathrm{CNO}$ and SIO. The pure spectra of $\mathrm{CB}, \mathrm{CNO}$, and SIO look similar (Figure 1); however, we can find some differences in some peaks. $\mathrm{CNO}$ has a peak at $1662.7 \mathrm{~cm}^{-1}$ whose intensity is lower. SIO has high intensity peaks at $1276.7 \mathrm{~cm}^{-1}$ and $3020.2 \mathrm{~cm}^{-1}$ that the others do not have. These peaks are assigned to plane $=\mathrm{CH}$ deforma- 
tion in an unconjugated cis $\mathrm{C}=\mathrm{C}$ and asymmetric $\mathrm{C}=\mathrm{H}$ stretch group. From Figure 2, we can see that the peak at $1745.3 \mathrm{~cm}^{-1}$ in CB is shown at $1747.93 \mathrm{~cm}^{-1}$ in $\mathrm{CNO}$ and at 1746.8 in SIO, and the peak at $1733.84 \mathrm{~cm}^{-1}$ in CB is shown at $1734.83 \mathrm{~cm}^{-1}$ in SIO. We found differences between the area ratios of the peaks at 1733.84 and $1745.43 \mathrm{~cm}^{-1}$, which can be used as differentiation patterns between $\mathrm{CB}, \mathrm{CNO}$, and SIO.

Table 2. Raman peaks for $\mathrm{CB}$ and vegetable oils.

\begin{tabular}{|c|c|c|c|}
\hline Assignments $^{1}$ & Cocoa Butter $\left(\mathrm{cm}^{-1}\right)$ & Coconut Oil $\left(\mathrm{cm}^{-1}\right)$ & Sacha Inchi Oil $\left(\mathrm{cm}^{-1}\right)$ \\
\hline$v_{\mathrm{as}}(\mathrm{C}-\mathrm{C}) \mathrm{T}$ & 1066.2 & 1069.3 & $\mathrm{Nd}$ \\
\hline$v(C-C) G$ & 1102.9 & 1092.4 & $\mathrm{Nd}$ \\
\hline$v_{\mathrm{S}}(\mathrm{C}-\mathrm{C})_{\mathrm{T}}$ & 1132.3 & 1132.3 & 1125.7 \\
\hline$\tau\left(\mathrm{CH}_{2}\right)$ & $\mathrm{Nd}$ & 1268.8 & $\mathrm{Nd}$ \\
\hline$\tau\left(\mathrm{CH}_{2}\right)$ & $\mathrm{Nd}$ & $\mathrm{Nd}$ & 1276.7 \\
\hline$\tau\left(\mathrm{CH}_{2}\right)$ & 1301.3 & 1303.4 & 1308.8 \\
\hline$\delta\left(\mathrm{CH}_{2}\right)$ & 1445.9 & 1445.1 & 1449.9 \\
\hline$\delta_{\mathrm{a}}\left(\mathrm{CH}_{3}\right)$ & 1462.9 & $\mathrm{Nd}$ & $\mathrm{Nd}$ \\
\hline$v_{\mathrm{s}}(\mathrm{C}=\mathrm{C})$ & 1662.3 & 1662.2 & 1662.7 \\
\hline$v(\mathrm{C}=\mathrm{O})$ & 1733.8 & $\mathrm{Nd}$ & 1734.8 \\
\hline$v(\mathrm{C}=\mathrm{O})$ & 1745.4 & 1747.9 & 1746.8 \\
\hline$v\left(\mathrm{CH}_{3}-\mathrm{CH}_{2}\right)$ & 2728.7 & 2730.8 & 2733.9 \\
\hline$v_{\mathrm{s}}\left(\mathrm{CH}_{2}\right)$ & 2855.7 & 2856.7 & 2863.4 \\
\hline$v_{\text {as }}\left(\mathrm{CH}_{2}\right)$ & 2886.1 & 2886.1 & 2907.6 \\
\hline$v_{\mathrm{s}}\left(\mathrm{CH}_{3}\right)$ & 2936.5 & 2932.3 & $\mathrm{Nd}$ \\
\hline$(=\mathrm{CH})^{2}$ & $\mathrm{Nd}$ & $\mathrm{Nd}$ & 3020.2 \\
\hline
\end{tabular}

${ }^{1}$ Assignments according to Bresson et al. [34], and Jiménez-Sanchidrián et al. [35].

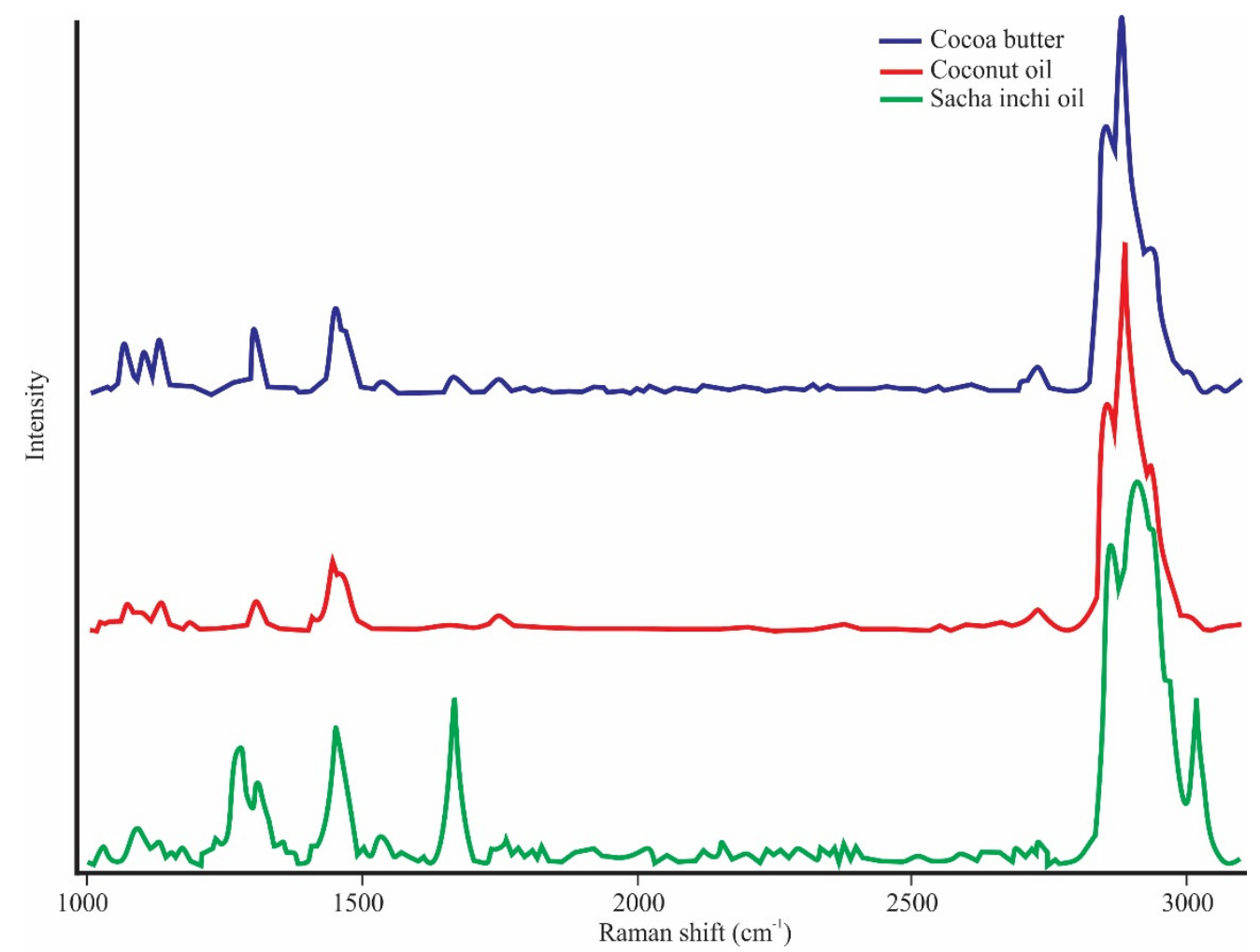

Figure 1. Raman spectra of the pure CB and vegetable oils in the full range $\left(1000-3100 \mathrm{~cm}^{-1}\right)$ at room temperature $\left(20^{\circ} \mathrm{C}\right)$. 


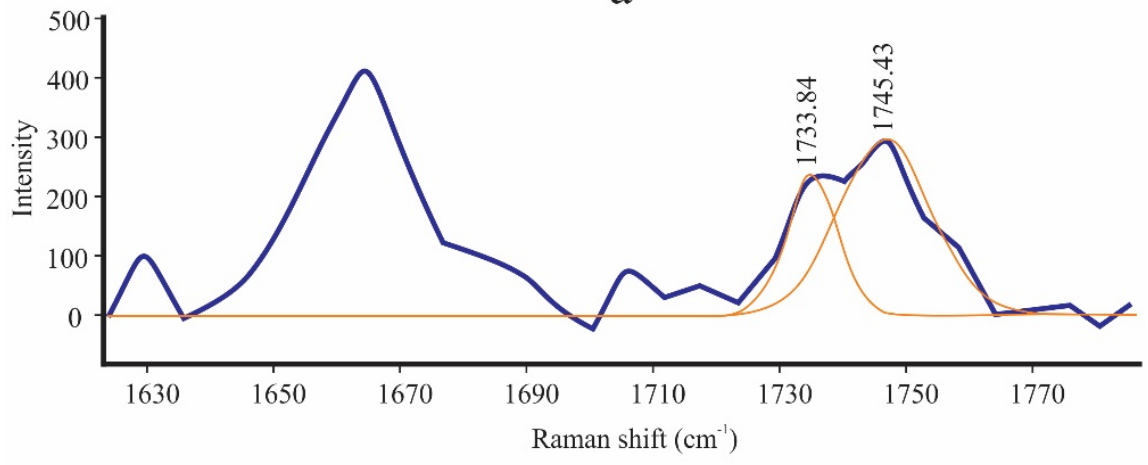

b

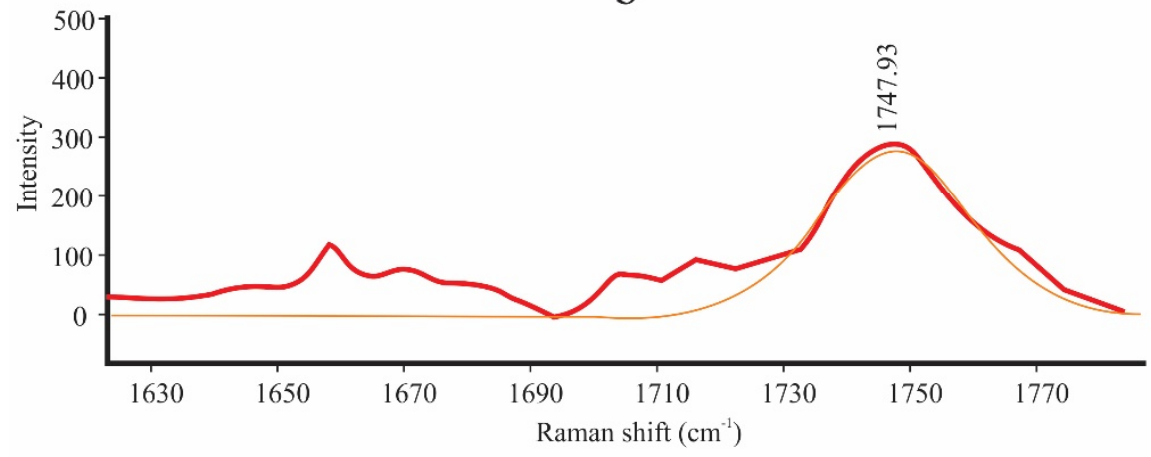

C

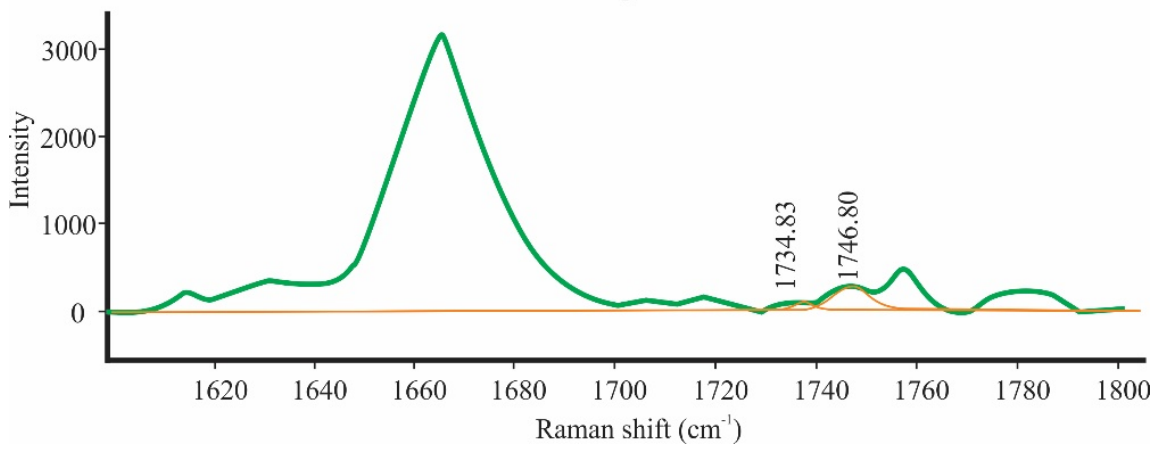

Figure 2. Carbonyl stretching region (1700-1780 $\mathrm{cm}^{-1}$ ) of $\mathrm{CB}$ and vegetable oils: (a) $\mathrm{CB}$; (b) $\mathrm{CNO}$; and (c) SIO.

Table 3 shows the area ratios and FWHM of $\mathrm{CB}, \mathrm{CNO}$, and SIO in the mode of vibrations $v(\mathrm{C}=\mathrm{O})$. The lower FWHM values indicate a better arrangement of the crystals and their solid state; therefore, at room temperature, the crystals of $\mathrm{CB}\left(17.38 \mathrm{~cm}^{-1}\right)$ would have a better arrangement than those of $\mathrm{CNO}\left(27.52 \mathrm{~cm}^{-1}\right)$, demonstrating its solid state.

Table 3. FWHM and area ratios of the components of the Gaussian function of Raman spectra of CB, $\mathrm{CNO}$, and SIO at room temperature $\left(\mathrm{T}=20^{\circ} \mathrm{C}\right)$.

\begin{tabular}{cccccc}
\hline \multirow{2}{*}{ Component } & \multicolumn{2}{c}{$\mathbf{1 7 3 3 . 8 4} \mathbf{~ c m}^{-\mathbf{1}}$} & \multicolumn{2}{c}{$\mathbf{1 7 4 5 . 4 3} \mathbf{~ c m}^{-\mathbf{1}}$} & \multicolumn{2}{c}{ Area Ratio } \\
\cline { 2 - 6 } & Area & FWHM & Area & FWHM & $\mathbf{A}_{\mathbf{1 7 3 3 . 8 4}} / \mathbf{A}_{\mathbf{1 7 4 5 . 4 3}}$ \\
\hline Sacha inchi oil & 288.19 & 3.99 & 2751.58 & 9.04 & 0.11 \\
Coconut oil & $\mathrm{Nd}$ & $\mathrm{Nd}$ & 8112.33 & 27.52 & $\mathrm{Nd}$ \\
Cocoa butter & 2448.96 & 9.85 & 5366.85 & 17.38 & 0.46 \\
\hline
\end{tabular}




\subsection{Miscibility of Cocoa Butter and Vegetable Oils}

Figure 3 shows the spectral range used for the miscibility analysis between $\mathrm{CB}, \mathrm{CNO}$, and SIO. The Raman spectra of the pure components are similar due to the similarity in their chemical composition. However, there are important differences that are considered for the analysis by MCR-ALS. These differences are mainly found in the $\mathrm{C}-\mathrm{C}$ stretching region $\left(1000-1200 \mathrm{~cm}^{-1}\right)$, the $C=C$ stretching $\left[v_{s}(C=C)\right]$, and the carbonyl $C=O$ stretching region (1700-1800 $\left.\mathrm{cm}^{-1}\right)$. The peak located at $1662.77 \mathrm{~cm}^{-1}$ has a greater intensity in the $\mathrm{SIO}$ than in $\mathrm{CB}$ and $\mathrm{CNO}$, and is characteristic of its liquid state.

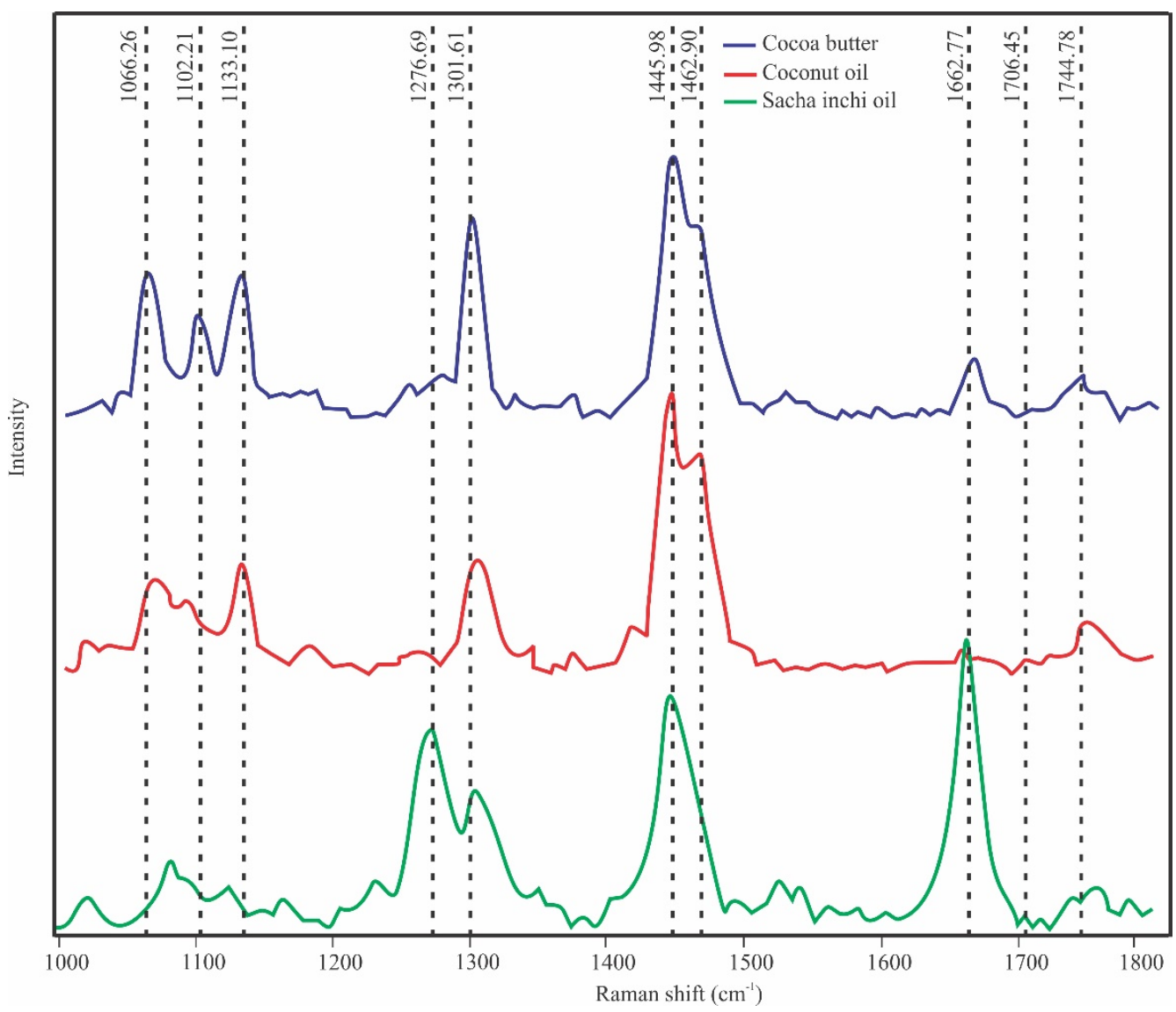

Figure 3. Raman spectral range used for analysis of the miscibility of $C B$ and vegetable oils by MCR-ALS.

Figure 4 shows the effect of the 1-norm preprocessing technique on the raw data from samples CB75-CNO25 (Figure 4a) and CB75-SIO25 (Figure 4c) obtained by Solo + MIA (original data in Supplementary Material). This method was able to correct the noise and scattering contributions in the raw data (Figure $4 \mathrm{~b}, \mathrm{~d}$ ) before fitting the data to the MCR-ALS model.

Table 4 shows the MCR-ALS quality parameters and correlation coefficients between the original spectra and the spectra recovered $\left(S^{T}\right)$ by MCR-ALS. The quality parameter related to the fit of the model was the percentage of explained variance, whose values were between 94.59 and $98.46 \%$, acceptable for our work. The use of the spectra of the pure compounds as equality constraints produced correlation coefficients between 0.9999 and 0.9993 . With these values, it can be verified that component 1 was related to CB and component 2 was related to vegetable oils ( $\mathrm{CNO}$ or $\mathrm{SIO}$ ) according to the analyzed samples. 
a

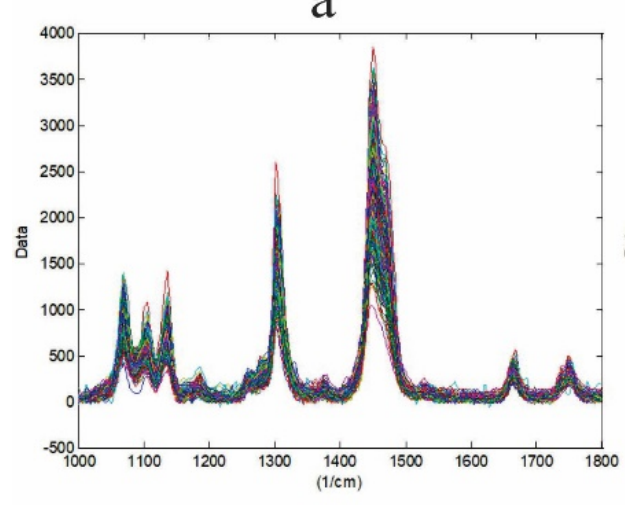

C

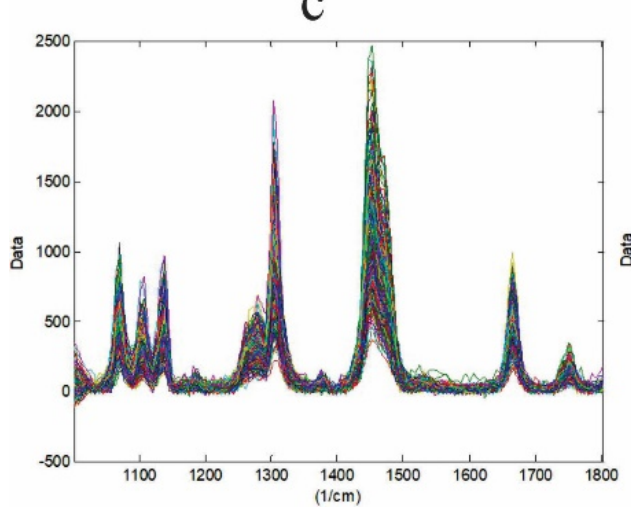

b

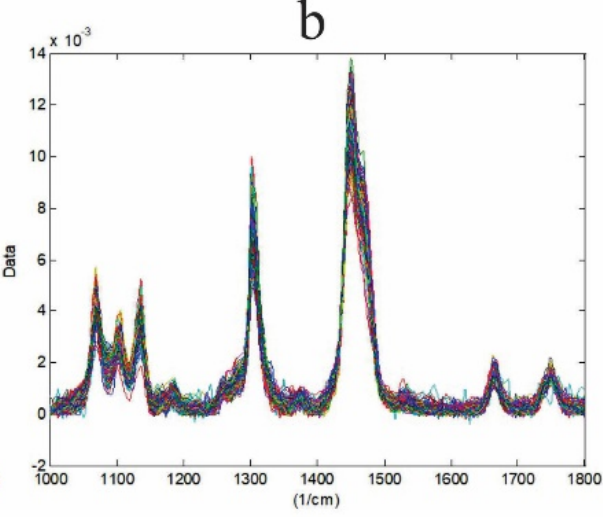

d

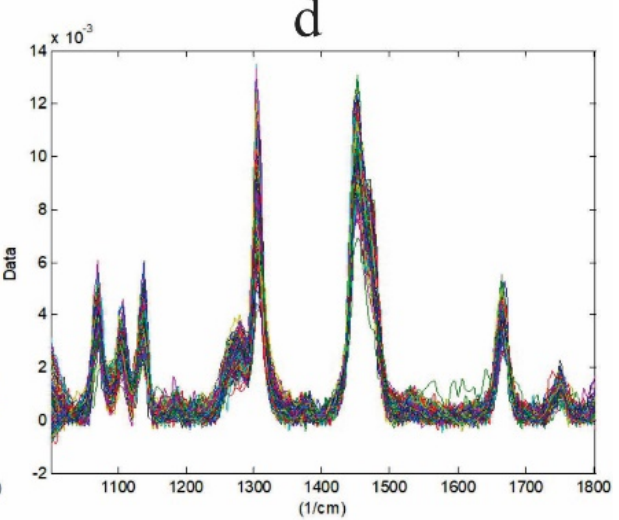

Figure 4. Raw data $(\mathbf{a}, \mathbf{c})$ and preprocessed data $(\mathbf{b}, \mathbf{d})$ from CB samples mixed with $25 \%$ CNO $(\mathbf{a}, \mathbf{b})$ and $25 \% \mathrm{SIO}(\mathbf{c}, \mathbf{d})$.

Table 4. MCR-ALS quality results and correlation coefficients between recovered spectra by the model and real spectra.

\begin{tabular}{|c|c|c|c|c|c|}
\hline Sample & $\begin{array}{c}\text { Numbers of } \\
\text { Factor }\end{array}$ & $\begin{array}{c}\text { Explained } \\
\text { Variance (\%) }\end{array}$ & $\begin{array}{l}\text { MCR-ALS } \\
\text { Component }\end{array}$ & Cocoa Butter & Vegetable Oil \\
\hline \multirow{2}{*}{ CB55-CNO45 } & \multirow{2}{*}{2} & \multirow{2}{*}{96.74} & Comp 1 & 0.9999 & 0.9396 \\
\hline & & & Comp 2 & 0.9384 & 0.9999 \\
\hline \multirow{2}{*}{ CB65-CNO35 } & \multirow{2}{*}{2} & \multirow{2}{*}{96.60} & Comp 1 & 0.9997 & 0.9546 \\
\hline & & & Comp 2 & 0.9397 & 0.9996 \\
\hline \multirow{2}{*}{ CB75-CNO25 } & \multirow{2}{*}{2} & \multirow{2}{*}{98.14} & Comp 1 & 0.9998 & 0.9378 \\
\hline & & & Comp 2 & 0.9401 & 0.9999 \\
\hline \multirow{2}{*}{ CB85-CNO15 } & \multirow[b]{2}{*}{2} & \multirow{2}{*}{98.46} & Comp 1 & 0.9996 & 0.9377 \\
\hline & & & Comp 2 & 0.9408 & 0.9999 \\
\hline \multirow{2}{*}{ CB95-CNO05 } & \multirow{2}{*}{2} & \multirow{2}{*}{92.76} & Comp 1 & 0.9999 & 0.9386 \\
\hline & & & Comp 2 & 0.9404 & 0.9998 \\
\hline \multirow{2}{*}{ CB55-SIO45 } & \multirow{2}{*}{2} & \multirow{2}{*}{94.59} & Comp 1 & 0.9998 & 0.5944 \\
\hline & & & Comp 2 & 0.6117 & 0.9993 \\
\hline \multirow{2}{*}{ CB65-SIO35 } & \multirow{2}{*}{2} & \multirow{2}{*}{97.46} & Comp 1 & 0.9999 & 0.5976 \\
\hline & & & Comp 2 & 0.6099 & 0.9995 \\
\hline \multirow{2}{*}{ CB75-SIO25 } & \multirow{2}{*}{2} & \multirow{2}{*}{97.99} & Comp 1 & 0.9998 & 0.9995 \\
\hline & & & Comp 2 & 0.6121 & 0.5976 \\
\hline \multirow{2}{*}{ CB85-SIO15 } & \multirow{2}{*}{2} & \multirow{2}{*}{98.01} & Comp 1 & 0.9999 & 0.5924 \\
\hline & & & Comp 2 & 0.6147 & 0.9993 \\
\hline \multirow{2}{*}{ CB95-SIO05 } & \multirow{2}{*}{2} & \multirow{2}{*}{97.39} & Comp 1 & 0.9997 & 0.5914 \\
\hline & & & Comp 2 & 0.6140 & 0.9995 \\
\hline
\end{tabular}


Figure 5 shows a comparison between the spectrum recovered $\left(S^{T}\right)$ by the MCR-ALS model and the original spectrum of the pure components. The restrictions used allowed for almost identical spectra with a good correlation. We can note that the spectrum of component 1 recovered by MCR-ALS is identical to the real spectra of CB (Figure 4a) and component 2 is identical to the real spectra of $\mathrm{CNO}$ (Figure $4 \mathrm{~b}$ ).

a

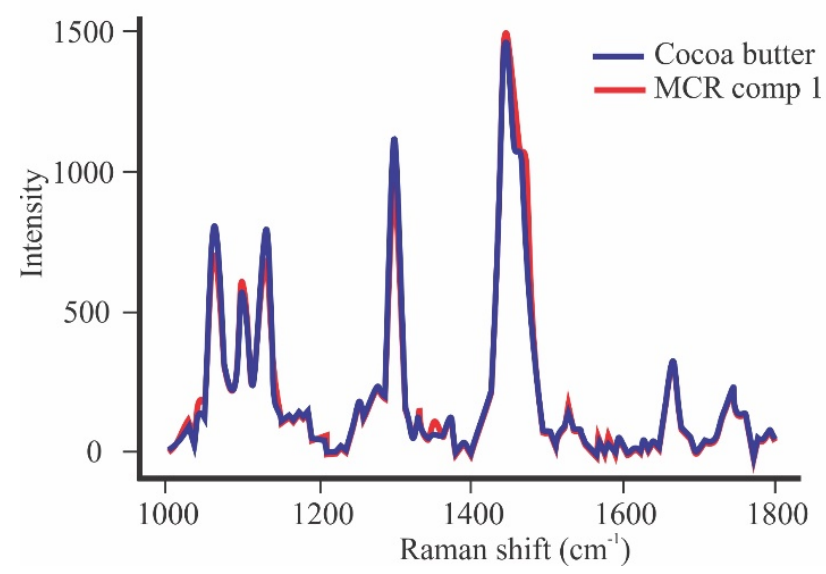

$\mathrm{b}$

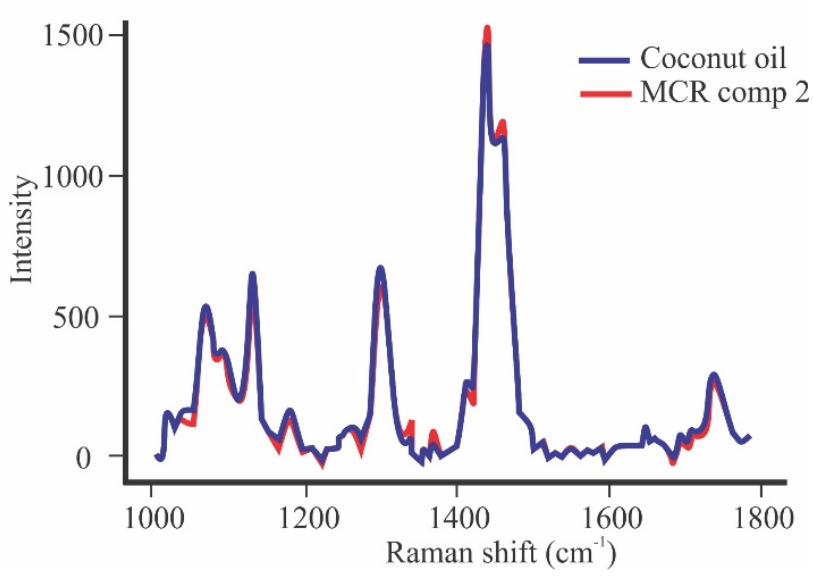

Figure 5. Comparison between the real spectra of the pure component and its respective spectrum recovered by MCR-ALS: (a) real and recovered spectra of $\mathrm{CB}$; (b) real and recovered spectra of $\mathrm{CNO}$.

Figure 6 shows the distribution maps and their corresponding histograms. These maps are constructed by the MCR-ALS model from the concentration matrix $C$ and show the distribution of the compounds in the blend. The reddest areas correspond to higher concentrations and the greenest areas correspond to the lowest concentrations. We can note that, in general, the histograms corresponding to the distribution maps are peak-shaped and symmetric, which indicates that both the $\mathrm{CNO}$ (Figure 5a-e) and the SIO (Figure 5f-j) form a homogeneous blend with the $\mathrm{CB}$. However, there are differences in the shapes between each histogram caused by the different concentrations of vegetable oil used in each sample.

Table 5 shows the quantitative analysis performed on the samples. The lowest RSD value of each component indicates its most homogeneous distribution in the sample. The RSD results show that CNO is more homogeneously distributed in the CB when its concentration is $45 \%$, while its distribution is less homogeneous at $15 \%$ or $5 \%$. The distribution of SIO in the sample is more homogeneous at $35 \%$ and less homogeneous at $15 \%$ or $5 \%$. With these results, we can affirm that the CNO is more miscible with CB than $\mathrm{SIO}$ and that the miscibility of both oils improves by increasing their concentrations in the sample. 


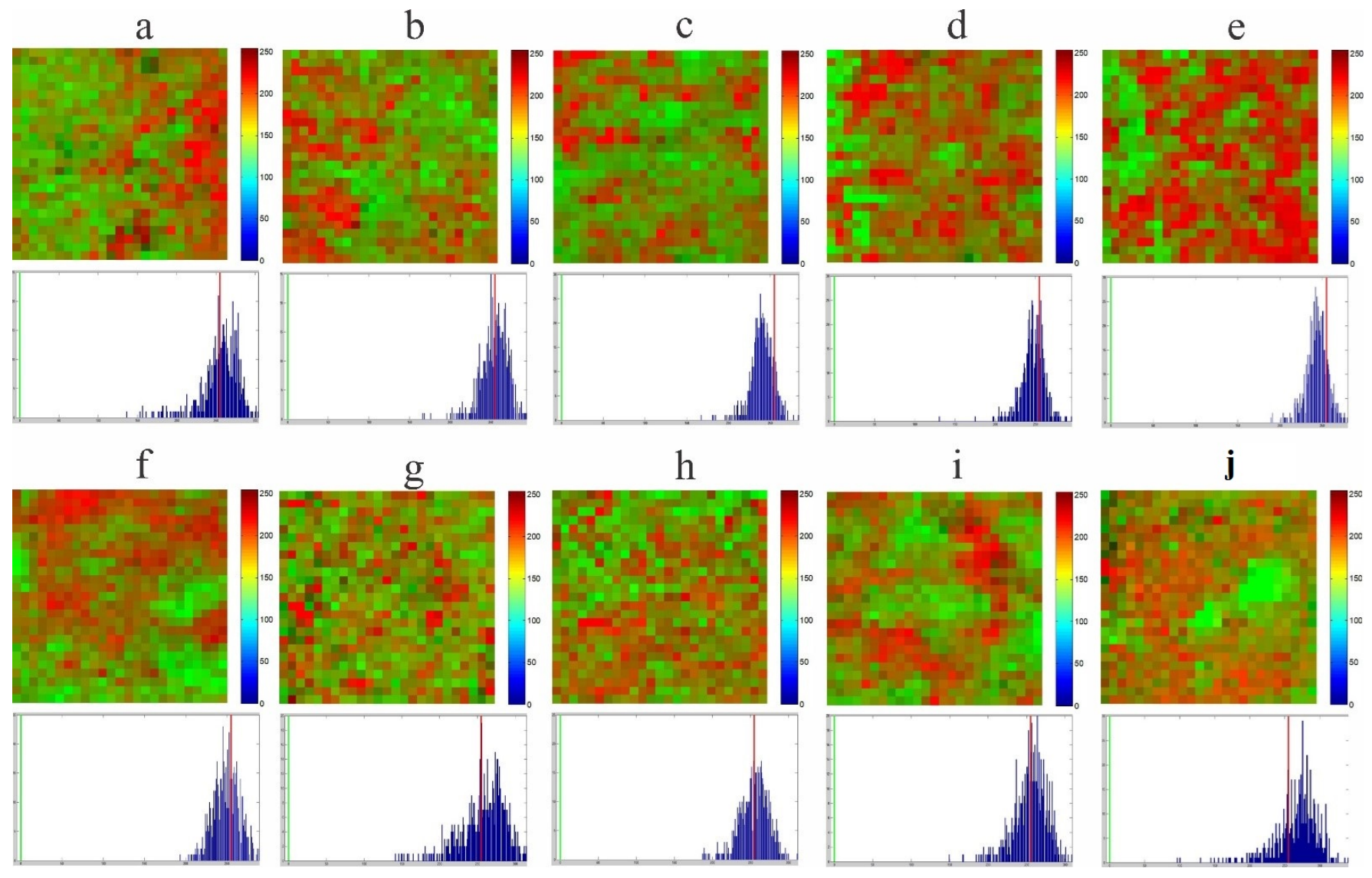

Figure 6. Distribution maps of the samples and their different concentrations: (a) CB55-CNO45; (b) CB65-CNO35; (c) CB75CNO25; (d) CB85-CNO15; (e) CB95-CNO05; (f) CB55-SIO45; (g) CB65-SIO35; (h) CB75-SIO25; (i) CB85-SIO15; (j) CB95-SIO05.

Table 5. Miscibility of vegetable oils with cocoa butter at different concentrations determined by their RSD.

\begin{tabular}{ccc}
\hline Sample & Cocoa Butter RSD $^{\mathbf{1}}$ & Vegetable Oil RSD $^{\mathbf{1}}$ \\
\hline CB55-CNO45 & $0.12 \pm 0.01^{\mathrm{ab}}$ & $0.09 \pm 0.02^{\mathrm{b}}$ \\
CB65-CNO35 & $0.17 \pm 0.03^{\mathrm{ab}}$ & $0.21 \pm 0.09^{\mathrm{ab}}$ \\
CB75-CNO25 & $0.23 \pm 0.06^{\mathrm{a}}$ & $0.29 \pm 0.09^{\mathrm{ab}}$ \\
CB85-CNO15 & $0.21 \pm 0.12^{\mathrm{a}}$ & $0.47 \pm 0.13^{\mathrm{a}}$ \\
CB95-CNO05 & $0.18 \pm 0.04^{\mathrm{ab}}$ & $0.44 \pm 0.23^{\mathrm{a}}$ \\
CB55-SIO45 & $0.12 \pm 0.02^{\mathrm{ab}}$ & $0.25 \pm 0.03^{\mathrm{ab}}$ \\
CB65-SIO35 & $0.10 \pm 0.01^{\mathrm{ab}}$ & $0.15 \pm 0.04^{\mathrm{b}}$ \\
CB75-SIO25 & $0.10 \pm 0.04^{\mathrm{ab}}$ & $0.18 \pm 0.04^{\mathrm{ab}}$ \\
CB85-SIO15 & $0.07 \pm 0.01^{\mathrm{b}}$ & $0.24 \pm 0.03^{\mathrm{ab}}$ \\
CB95-SIO05 & $0.07 \pm 0.02^{\mathrm{b}}$ & $0.19 \pm 0.03^{\mathrm{ab}}$ \\
\hline
\end{tabular}

${ }^{1}$ Different letters $(a, b)$ in the same column represent significant differences $(p \leq 0.05)$.

\section{Discussion}

\subsection{Characterization of the Spectra of Cocoa Butter and Vegetable Oils}

According to Carmona et al. [36], the spectra were examined separately in the wavenumber region from 1000 to $3100 \mathrm{~cm}^{-1}$ to find differences between them. Then, although the spectra for edible vegetable oils were similar (Figure 1), it could be seen that they exhibit some differences which are small but enable their discrimination [35]. Wang et al. [37] reported a peak at $3016 \mathrm{~cm}^{-1}$ in the Chinese-specific peony seed oil spectrum. This peak is located in the region $=\mathrm{C}-\mathrm{H}$ stretching vibration of the methyl linoleate group (cis, cis diene) of $\mathrm{RCH}=\mathrm{CHR}$, and it is used in the evaluation of oils with different unsaturation degrees. The 
SIO spectrum has a peak at $3020.2 \mathrm{~cm}^{-1}$ (Figure 1, Table 2) that is not present in CB and $\mathrm{CNO}$. This peak demonstrates the degree of unsaturation of the SIO. In the characterization of the Raman spectra of $\mathrm{CB}$ at $22{ }^{\circ} \mathrm{C}$ carried out by Bresson et al. [34], 2 peaks were reported at 1744 and $1732 \mathrm{~cm}^{-1}$, which are representative of forms III and IV. In the present work, these peaks were identified at 1745.4 and $1733.8 \mathrm{~cm}^{-1}$ (Figure 2, Table 2) and show that the existing conformational differences depend on the CB polymorphism. Bresson et al. [38] observed 3 components between 1750 and $1725 \mathrm{~cm}^{-1}, 1730,1735$, and $1744 \mathrm{~cm}^{-1}$, which were attributed to the peak at $1735 \mathrm{~cm}^{-1}$ in $\mathrm{CB}$ or the peak at $1736 \mathrm{~cm}^{-1}$ in $\mathrm{CBE}$ for form $\mathrm{V}$ or VI. This peak was not observed in the $\mathrm{CB}, \mathrm{CNO}$, and SIO spectra (Figure 2, Table 3), so we can deduce that the $\mathrm{V}$ form was not present in the $\mathrm{CB}$; therefore, the previous statement is corroborated.

In the olefinic band in the $C=C$ stretching range $\left(1200-1800 \mathrm{~cm}^{-1}\right)$, Bresson et al. [34] attributed the liquid form of $C B$ to the intensity of the peak located at $1661 \mathrm{~cm}^{-1}$, as well as to the functional group present in oleic acid. That is, the higher intensity of this peak characterizes the liquid state of $\mathrm{CB}$, and the lower intensity characterizes the solid state (form IV). This coincides with what is observed in Figure 2a,c, in which this peak is located at $1662.7 \mathrm{~cm}^{-1}$ in CB, CNO, and SIO. There is a noticeable difference in the intensity of this peak, since it is higher in the SIO, which determines its liquid state at room temperature and its proportion of oleic acid. Likewise, this peak was observed at $1658 \mathrm{~cm}^{-1}$ by De Géa Neves et al. [18] in the Raman spectrum of CNO and was used as a differentiating pattern between $\mathrm{CNO}$ and other vegetable oils. The peak at $1445 \mathrm{~cm}^{-1}$ is related to the $\mathrm{C}-\mathrm{H}$ deformation vibration, and the peak at $1658 \mathrm{~cm}^{-1}$ is assigned to $c i s \mathrm{C}=\mathrm{C}$ bonds, both of which provide the degree of unsaturation value $[35,37]$. Therefore, these peaks can be useful to determine the degree of unsaturation of $\mathrm{CB}, \mathrm{CNO}$, and SIO.

In the CB spectra, the stretching C-C region $\left(1030-1183 \mathrm{~cm}^{-1}\right)$ allows its different polyforms to be identified. According to Bresson et al. [34], the existence of three peaks $\left(1066.26,1102.21\right.$, and $1133.10 \mathrm{~cm}^{-1}$ ) (Figure 3) at room temperature allows us to recognize that it is the IV or V form and the solid state of CB. The physical state of these ingredients must also be taken into account; that is, at room temperature, the semisolid CNO only presented a peak at $1133.10 \mathrm{~cm}^{-1}$, and the liquid SIO did not present any peak in this region. This characteristic of the SIO spectrum agrees with the spectra of peony seed oil, soybean oil, and extra virgin olive oil reported by Wang et al. [37]. Bresson et al. [34] affirms that the peak at $1100 \mathrm{~cm}^{-1}$ is representative of the solid state of $C B$ and is not shown in the liquid state. This statement agrees with our results, since these peaks are not seen in $\mathrm{CNO}$ and SIO, which are not solid at room temperature.

To find differentiation patterns between CB and CBE, Bresson et al. [38] identified peaks at 1744,1735 , and $1730 \mathrm{~cm}^{-1}$ and found notable differences between the area ratios of these peaks. The results in Table 3 indicate that only two peaks were identified at 1733.84 and $1745.43 \mathrm{~cm}^{-1}$, which correspond to the peaks mentioned above. The area ratios of $\mathrm{CB}$ and SIO are very different, making their differentiation possible. It was not possible to calculate the area ratio for the $\mathrm{CNO}$ because the peak at $1733.84 \mathrm{~cm}^{-1}$ was not found. FWHM is also an indicator of polymorphism in the sense that a decrease in this value indicates the transition of $\mathrm{CB}$ from a liquid to a solid due to the better arrangement of the crystals [34]. This statement agrees with the results of Table 3, since the semisolid state of $\mathrm{CNO}$ will produce a higher FWHM than $\mathrm{CB}$, which is solid at room temperature. The same behavior does not occur with SIO, since this vegetable oil is completely liquid at room temperature.

\subsection{Miscibility of Cocoa Butter and Vegetable Oils}

Following Mitsutake et al. [22], to start the analysis by MCR-ALS, the Raman range from 1000 to $1800 \mathrm{~cm}^{-1}$ was chosen, because it contains those peaks that allow differences to be found between the three materials studied. Therefore, Figure 3 shows the range of analysis and the main peaks that differentiate $\mathrm{CB}$ from $\mathrm{CNO}$ and SIO. The most striking difference is the high intensity of the peak of the SIO spectrum located at $1662.77 \mathrm{~cm}$, which is 
related to its liquid state at room temperature. On the other hand, De Géa Neves et al. [18] reported the existence of peaks at 1264 and $1658 \mathrm{~cm}^{-1}$ in the CNO spectrum that differentiated it from other vegetable oils. In the present work, these peaks were shown at 1268.8 and $1662.2 \mathrm{~cm}^{-1}$, and their intensity was very low with respect to CB and SIO. According to Castro et al. [39], to remove noise signals and optimize the results of the MCR-ALS model, the data were preprocessed using the Savitzky-Golay filter from LabSpec 6 and the 1-norm normalization method from Solo + MIA. Figure $4 \mathrm{~b}$,d shows the preprocessed data showing low scattering contributions, with which they were corrected, obtaining acceptable results according to Zhang et al. $[39,40]$.

The analysis of mixtures has been a constant concern in any scientific domain [41]. MCR-ALS solves this problem by providing a chemically (scientifically) significant additive bi-linear model of pure contributions from an original data matrix [30]. This bilinear model could produce several solutions, known as rotational ambiguity, which is the primary source of uncertainty. Thus, selecting the appropriate constraints is essential to obtain optimal solutions [30,41,42]. Once the optimization process has been finished, the MCRALS results are the set of concentration profiles, spectra and quality parameters (explained variance) related to the model [30]. Therefore, nonnegativity and equality restrictions were applied to our data. With these considerations, the explained variance of the MCR-ALS model for all samples was between 94.59 and $98.46 \%$ (Table 4), which means that this model is capable of representing the original data with high precision. Mitsusake et al. [22] reported explained variance percentages between 98.9 and $99.6 \%$ in MCR-ALS when it was applied to blends formulated using natural excipients, and Zhang et al. [40] reported values between 99.43 and $99.56 \%$ in the analysis of the constituents of commercial chocolate samples. The authors conclude that their results are well adjusted, and therefore, the MCR-ALS model is capable of constructing chemical maps of the samples. Although these values are higher than the results found in our work, we can say that our data fit the MCR-ALS model in such percentages.

Zhang et al. [40] worked with white chocolates, making a comparison between the spectrum of the pure components such as sucrose, lactose, butter and whey. The correlation coefficients between the pure spectra and those recovered by MCR-ALS with data preprocessing were between 0.6701 and 0.9910 , which were considered satisfactory. The equality constraint fixes the recovered spectra or concentrations to specific known values [43]. This is the reason why the values of the correlation coefficient between the recovered spectra and the pure compounds are high (Table 4). Additionally, Figure 5 shows that there is no rotational ambiguity, because the recovered spectra $\left(S^{T}\right)$ are identical to the original spectra. The same results were obtained for the other samples. Based on these results, we can affirm that the first spectrum recovered by MCR-ALS (component 1) corresponds to $\mathrm{CB}$, while the second spectrum (component 2) corresponds to vegetable oil, according to the sample analyzed.

The mathematical analysis of each image allows for the extraction of parameters that are helpful in the interpretation of the images and in understanding of the blending process studied [31]. The data provided by Raman mapping contain spectral and spatial information; then, MCR-ALS can be used to visualize the concentration distribution maps of the different components present in a sample based on their individual spectral signals [44]. However, the quality of the Raman mapping is limited by the spectra of the individual compounds and their concentration, so the analysis becomes complex if the spectra of the components have common peaks [21], as is the case with $\mathrm{CB}, \mathrm{CNO}$ and SIO (Figure 3). This was another reason why we decided to use the spectra of the pure compounds as equality constraints. It is important to mention that the values in matrix $C$ are related to the concentrations, but they are not the real concentrations of the components of the blends, so the mean value should not be compared with the real concentration of each component [22]. Figure 6 shows the distribution maps of $\mathrm{CB}, \mathrm{CNO}$, and SIO in all the samples analyzed constructed from the matrix of concentrations $C$ obtained by MCR-ALS. Figure 6a shows a better distribution of CB and CNO at concentrations of 55 
and $45 \%$, respectively. Similarly, Figure $6 \mathrm{~g}$ shows a better distribution of CB and SIO at concentrations of 65 and 35\%, respectively. Both figures show better distribution than the others. Similar results were obtained by Scoutaris et al. [21] when analyzing mixtures of paracetamol (PMOL) and compritol 888 (C-888).

We consider that the miscibility of two components can be determined by their distribution in a chemical map, and homogeneous distribution is an indicator of good miscibility. The homogeneity of the samples is also analyzed using the histograms of the distribution map. According to Gendrin et al. [45], a histogram that exhibits a symmetric distribution with a narrow base and a sharp peak is representative of an image with a low contrast, and therefore a homogeneous sample. The histograms corresponding to each distribution map show a symmetric shape in all cases (Figure 6), with differences according to the actual concentration of each sample. Lyon et al. [46] prepared tablets composed of furosemide and excipients at five different degrees of mixing, reporting that the most homogeneous distribution was obtained in those samples whose histograms were symmetric.

The homogeneity of the samples can be quantitatively analyzed using the RSD. According to Scoutaris et al. [21], RSD has been used to compare the homogeneity of a sample; a low RSD value is interpreted as signifying higher homogeneity. Mitsusake et al. [22] showed that the standard deviation of histograms (STD) is used to evaluate the miscibility for the preformulation stage of pharmaceutical tablets. Therefore, we consider that both parameters are comparable. Lyon et al. [46] used the RSD of the histograms generated by the image scores to determine the homogeneity of the distribution of furosemide in tablets, observing a progressive increase in RSD as the degree of homogeneity decreased. Mitsutake et al. [22] observed an intermediate miscibility $(\mathrm{STD}=6.9)$ between $\mathrm{CB}$ and $\mathrm{CNO}$ at real concentrations of 75 and $25 \%$, respectively. Similar results were obtained in the present study (Table 5), in which it is shown that blends containing $45 \% \mathrm{CNO}$ and $35 \% \mathrm{SIO}$ have the lowest RSD; therefore, they form a more homogeneous blend with CB and are more miscible at those concentrations. In the elaboration of CBEs, the candidate vegetable oil must have an SOS triglyceride concentration similar to that of CB. To achieve this, it undergoes a fractionation process [8]. In the case of $\mathrm{CNO}$ and $\mathrm{SIO}$, they were used in their natural state, showing good miscibility with $\mathrm{CB}$; therefore, they would be good candidates to be used as CBE.

Food products are complex mixtures of heterogeneous nature; obtaining chemical and spatial information from them is crucial for food safety and quality control [47]. For this, food detection technologies play a fundamental role [25]; therefore, it is urgent to develop rapid methods of nondestructive analysis to control the quality and safety of food and thus control its circulation in the market [47]. Chemical Raman imaging (CRI), in combination with chemometrics, can provide spectral information and spatial distributions of specific chemicals, analyzing them non-destructively [42,47-50]. However, in the food field, only a few investigations on the application of CRI have been reported [50]. CRM allows the application of Raman mapping with MCR-ALS to obtain the chemical characteristics of $\mathrm{CB}, \mathrm{CNO}$, and $\mathrm{SIO}$ through their Raman spectral fingerprint (Figure 1) and to identify the miscibility of these three components (Figure 6, Table 5), which demonstrates the usefulness of this methodology in initiating the development of new products in the chocolate industry. Some authors have also used this methodology, such as Liu et al. [51], who used chemical Raman mapping to study the compatibility between hydroxypropyl methylcellulose (HPMC) and gelatin. It was found that HPMC was easily adapted to form continuous and intermediate phases from the molecular interactions between both components. Mitsutake et al. [52] studied the miscibility and structural changes (polymorphism) in mixtures of natural and synthetic beeswax (BW) with copaiba oil using Raman mapping and MCR-ALS. Structural changes were found in the synthetic BWs, and the miscibility between both BWs with copaiba oil was not significantly different. It was also observed that the differences between the freshly prepared mixtures and those with three months of storage were more significant when the amount of oil was increased. On the other hand, 
Rodríguez et al. [12] studied the compatibility of shea butter and CB mixtures using the isosolid diagram but did not use Raman mapping.

Lauric acid and partially hydrogenated fats are not recommended in the chocolate industry because they can increase LDL cholesterol levels [53]. Norazlina et al. [2] reported the following CBE candidates: mean fraction of palm oil, mango seed fat, shea stearin, kokum fat, illipe butter, high oleic and stearic sunflower oil, palm stearin, and bambangan kernel fat. However, this author does not report CNO and SIO. The results of the present work show $\mathrm{CNO}$ and $\mathrm{SIO}$ as possible candidates for novel $\mathrm{CBE}$, as they demonstrate some advantages, such as their high degree of unsaturation, which makes them healthy fats, as well as their excellent molecular compatibility with $\mathrm{CB}$ demonstrated by their miscibility. However, it is necessary to carry out some additional studies, such as the investigation of their thermal and rheological properties at different concentrations of solid and liquid lipids and the investigation of their behaviors over time.

\section{Conclusions}

In the present work, the usefulness of the confocal Raman microscopy (CRM) technique to identify the chemical properties of cocoa butter, coconut oil and sacha inchi oil is demonstrated. These latter vegetable oils are proposed as candidates to be cocoa butter equivalents in the manufacture of chocolates. The main differences are in the physical state and the degree of unsaturation, which are differentiated by the intensity of the peaks in the Raman spectra. Likewise, the usefulness of the chemometric technique known as multivariate curve resolution-alternating least squares to analyze the miscibility of these vegetable oils with cocoa butter is demonstrated. We conclude that coconut oil is more miscible with cocoa butter at a $45 \%$ concentration, and sacha inchi oil is more miscible at a $35 \%$ concentration. Between the two vegetable oils, coconut oil is more miscible than sacha inchi oil. We consider that this work is the first step in finding novel CBEs for developing new chocolates. Further work is necessary to evaluate their thermal, rheological, and sensorial properties.

Supplementary Materials: The following are available online at https:/ /www.mdpi.com/article/10 .3390/foods10123101/s1, map blend: CB-CNO; CB-SIO and pure spectrum: CB; CNO; SIO.

Author Contributions: Conceptualization, E.M.C.-A. and F.P.C.-T.; methodology, E.M.C.-A., F.P.C.-T. and L.T.-V.; software, E.M.C.-A. and L.T.-V.; validation, E.M.C.-A.; formal analysis, E.M.C.-A., F.P.C.-T. and I.S.C.-C.; investigation, E.M.C.-A.; resources, I.S.C.-C.; data curation, E.M.C.-A.; writing-original draft preparation, E.M.C.-A., F.P.C.-T. and I.S.C.-C.; writing-review and editing, E.M.C.-A., F.P.C.-T. and I.S.C.-C.; visualization, E.M.C.-A. and I.S.C.-C.; supervision, E.M.C.-A. and F.P.C.-T.; project administration, I.S.C.-C.; funding acquisition, I.S.C.-C. All authors have read and agreed to the published version of the manuscript.

Funding: This research was funded by the Consejo Nacional de Ciencia, Tecnología e Innovación Tecnológica-Concytec (Project: Equipamiento Científico 2018-01/E044-2018-01-BM, Contrato No 0122018-Fondecyt/BM) of the Peruvian Government, The World Bank Group, the Universidad Nacional Toribio Rodríguez de Mendoza de Amazonas and the Pontificia Universidad Católica del Perú. The APC was funded by the Consejo Nacional de Ciencia, Tecnología e Innovación Tecnológica-Concytec.

Institutional Review Board Statement: Not applicable.

Informed Consent Statement: Not applicable.

Data Availability Statement: Not applicable.

Acknowledgments: The authors thank the Cooperativa de Servicios Múltiples APROCAM for the facilities provided during the execution of this work.

Conflicts of Interest: The authors declare no conflict of interest. 


\section{References}

1. Ewens, H.; Metilli, L.; Simone, E. Analysis of the effect of recent reformulation strategies on the crystallization behaviour of cocoa butter and the structural properties of chocolate. Curr. Res. Food Sci. 2021, 4, 105-114. [CrossRef]

2. Norazlina, M.; Jahurul, M.; Hasmadi, M.; Mansoor, A.; Norliza, J.; Patricia, M.; George, M.R.; Noorakmar, A.; Lee, J.; Fan, H. Trends in blending vegetable fats and oils for cocoa butter alternative application: A review. Trends Food Sci. Technol. 2021, 116, 102-114. [CrossRef]

3. Watanabe, S.; Yoshikawa, S.; Sato, K. Formation and properties of dark chocolate prepared using fat mixtures of cocoa butter and symmetric/asymmetric stearic-oleic mixed-acid triacylglycerols: Impact of molecular compound crystals. Food Chem. 2021, 339, 127808. [CrossRef] [PubMed]

4. Toro-Vazquez, J.F.; Charó-Alonso, M.A.; Morales-Rueda, J.A.; Pérez-Martínez, J.D. Molecular Interactions of Triacylglycerides in Blends of Cocoa Butter with trans-free Vegetable Oils. In Cocoa Butter and Related Compounds; AOCS Press: Urbana, IL, USA, 2012; pp. 393-416.

5. Bootello, M.A.; Hartel, R.W.; Garcés, R.; Martínez-Force, E.; Salas, J.J. Evaluation of high oleic-high stearic sunflower hard stearins for cocoa butter equivalent formulation. Food Chem. 2012, 134, 1409-1417. [CrossRef] [PubMed]

6. Bahari, A.; Akoh, C.C. Texture, rheology and fat bloom study of 'chocolates' made from cocoa butter equivalent synthesized from illipe butter and palm mid-fraction. LWT-Food Sci. Technol. 2018, 97, 349-354. [CrossRef]

7. Jahurul, M.; Zaidul, I.; Norulaini, N.; Sahena, F.; Jinap, S.; Azmir, J.; Sharif, K.; Omar, A.M. Cocoa butter fats and possibilities of substitution in food products concerning cocoa varieties, alternative sources, extraction methods, composition, and characteristics. J. Food Eng. 2013, 117, 467-476. [CrossRef]

8. Segman, O.; Wiesman, Z.; Yarmolinsky, L. Methods Ant Technologies Related to Shea Butter Chemophysical Properties and to the Delivery of Bioactives in Chocolate and Related Products. In Cocoa Butter and Related Compounds; AOCS Press: Urbana, IL, USA, 2012; pp. 417-441.

9. Kang, K.K.; Jeon, H.; Kim, I.-H.; Kim, B.H. Cocoa butter equivalents prepared by blending fractionated palm stearin and shea stearin. Food Sci. Biotechnol. 2013, 22, 347-352. [CrossRef]

10. Talbot, G. Chocolate and Cocoa Butter-Structure and Composition. In Cocoa Butter and Related Compounds; AOCS Press: Urbana, IL, USA, 2012; pp. 1-34. ISBN 978-0-9830791-2-5.

11. Beckett, T.S. Industrial Chocolate Manufacture and Use, 4th ed.; Wiley-Blackwell: Chichester, UK, 2009; ISBN 978-1-4051-3949-6.

12. Rodriguez-Negrette, A.C.; Huck-Iriart, C.; Herrera, M.L. Physical Chemical Properties of Shea/Cocoa Butter Blends and their Potential for Chocolate Manufacture. J. Am. Oil Chem. Soc. 2019, 96, 239-248. [CrossRef]

13. EUR-Lex Directive 2000/36/EC of the European Parliament and of the Council of 23 June 2000 Relating to Cocoa and Chocolate Products Intended for Human Consumption. Available online: https: / eur-lex.europa.eu/eli/dir/2000/36/2013-11-18 (accessed on 2 December 2021).

14. CFR Code of Federal Regulations. Title 21-Part 163: Cacao Products. Available online: https://www.ecfr.gov/current/title-21 / chapter-I/subchapter-B/part-163 (accessed on 2 December 2021).

15. Medina-Mendoza, M.; Rodriguez-Pérez, R.J.; Rojas-Ocampo, E.; Torrejón-Valqui, L.; Fernández-Jeri, A.B.; Idrogo-Vásquez, G.; Cayo-Colca, I.S.; Castro-Alayo, E.M. Rheological, bioactive properties and sensory preferences of dark chocolates with partial incorporation of Sacha Inchi (Plukenetia volubilis L.) oil. Heliyon 2021, 7, e06154. [CrossRef]

16. Chirinos, R.; Zuloeta, G.; Pedreschi, R.; Mignolet, E.; Larondelle, Y.; Campos, D. Sacha inchi (Plukenetia volubilis): A seed source of polyunsaturated fatty acids, tocopherols, phytosterols, phenolic compounds and antioxidant capacity. Food Chem. 2013, 141, 1732-1739. [CrossRef]

17. Ramos-Escudero, F.; Morales, M.T.; Escudero, M.R.; Muñoz, A.M.; Chavez, K.C.; Asuero, A.G. Assessment of phenolic and volatile compounds of commercial Sacha inchi oils and sensory evaluation. Food Res. Int. 2021, 140, 110022. [CrossRef]

18. Neves, M.D.G.; Poppi, R.J. Monitoring of Adulteration and Purity in Coconut Oil Using Raman Spectroscopy and Multivariate Curve Resolution. Food Anal. Methods 2017, 11, 1897-1905. [CrossRef]

19. Jayawardena, R.; Swarnamali, H.; Ranasinghe, P.; Misra, A. Health effects of coconut oil: Summary of evidence from systematic reviews and meta-analysis of interventional studies. Diabetes Metab. Syndr. Clin. Res. Rev. 2021, 15, 549-555. [CrossRef] [PubMed]

20. da Silva, G.H.R.; Ribeiro, L.N.; Mitsutake, H.; Guilherme, V.A.; DE Castro, S.; Poppi, R.; Breitkreitz, M.C.; de Paula, E. Optimised NLC: A nanotechnological approach to improve the anaesthetic effect of bupivacaine. Int. J. Pharm. 2017, 529, 253-263. [CrossRef]

21. Scoutaris, N.; Vithani, K.; Slipper, I.; Chowdhry, B.; Douroumis, D. SEM/EDX and confocal Raman microscopy as complementary tools for the characterization of pharmaceutical tablets. Int. J. Pharm. 2014, 470, 88-98. [CrossRef] [PubMed]

22. Mitsutake, H.; Ribeiro, L.N.; da Silva, G.H.R.; Castro, S.R.; de Paula, E.; Poppi, R.; Breitkreitz, M.C. Evaluation of miscibility and polymorphism of synthetic and natural lipids for nanostructured lipid carrier (NLC) formulations by Raman mapping and multivariate curve resolution (MCR). Eur. J. Pharm. Sci. 2019, 135, 51-59. [CrossRef]

23. Mitsutake, H.; DE Castro, S.; de Paula, E.; Poppi, R.; Rutledge, D.N.; Breitkreitz, M.C. Comparison of different chemometric methods to extract chemical and physical information from Raman images of homogeneous and heterogeneous semi-solid pharmaceutical formulations. Int. J. Pharm. 2018, 552, 119-129. [CrossRef]

24. Breitkreitz, M.C.; Sabin, G.P.; Polla, G.; Poppi, R. Characterization of semi-solid Self-Emulsifying Drug Delivery Systems (SEDDS) of atorvastatin calcium by Raman image spectroscopy and chemometrics. J. Pharm. Biomed. Anal. 2013, 73, 3-12. [CrossRef] 
25. Petersen, M.; Yu, Z.; Lu, X. Application of Raman Spectroscopic Methods in Food Safety: A Review. Biosensors 2021, $11,187$. [CrossRef]

26. Yaseen, T.; Sun, D.-W.; Cheng, J.-H. Raman imaging for food quality and safety evaluation: Fundamentals and applications. Trends Food Sci. Technol. 2017, 62, 177-189. [CrossRef]

27. Liu, X.; Zhang, N.; Yu, L.; Zhou, S.; Shanks, R.; Zheng, J. Imaging the phase of starch-gelatin blends by confocal Raman microscopy. Food Hydrocoll. 2016, 60, 7-10. [CrossRef]

28. Neves, A.C.d.O.; Zougagh, M.; Ríos, Á.; Tauler, R.; Wakamatsu, K.; Galván, I. Pheomelanin Subunit Non-Destructive Quantification by Raman Spectroscopy and Multivariate Curve Resolution-Alternating Least Squares (MCR-ALS). Chemom. Intell. Lab. Syst. 2021, 217, 104406. [CrossRef]

29. Vajna, B.; Pataki, H.; Nagy, Z.; Farkas, I.; Marosi, G. Characterization of melt extruded and conventional Isoptin formulations using Raman chemical imaging and chemometrics. Int. J. Pharm. 2011, 419, 107-113. [CrossRef] [PubMed]

30. de Juan, A.; Jaumot, J.; Tauler, R. Multivariate Curve Resolution (MCR). Solving the mixture analysis problem. Anal. Methods 2014, 6, 4964-4976. [CrossRef]

31. Osorio, J.G.; Stuessy, G.; Kemeny, G.J.; Muzzio, F.J. Characterization of pharmaceutical powder blends using in situ near-infrared chemical imaging. Chem. Eng. Sci. 2014, 108, 244-257. [CrossRef]

32. Amigo, J.M. Practical issues of hyperspectral imaging analysis of solid dosage forms. Anal. Bioanal. Chem. 2010, 398, 93-109. [CrossRef]

33. Gendrin, C.; Roggo, Y.; Collet, C. Pharmaceutical applications of vibrational chemical imaging and chemometrics: A review. J. Pharm. Biomed. Anal. 2008, 48, 533-553. [CrossRef] [PubMed]

34. Bresson, S.; Rousseau, D.; Ghosh, S.; El Marssi, M.; Faivre, V. Raman spectroscopy of the polymorphic forms and liquid state of cocoa butter. Eur. J. Lipid Sci. Technol. 2011, 113, 992-1004. [CrossRef]

35. Jiménez-Sanchidrián, C.; Ruiz, J.R. Use of Raman spectroscopy for analyzing edible vegetable oils. Appl. Spectrosc. Rev. 2016, 51, 417-430. [CrossRef]

36. Carmona, M.Á.; Lafont, F.; Jiménez-Sanchidrián, C.; Ruiz, J.R. Raman spectroscopy study of edible oils and determination of the oxidative stability at frying temperatures: Raman Spectroscopy Study of Edible Oils. Eur. J. Lipid Sci. Technol. 2014, 116, 1451-1456. [CrossRef]

37. Wang, H.; Xin, Y.; Ma, H.; Fang, P.; Li, C.; Wan, X.; He, Z.; Jia, J.; Ling, Z. Rapid detection of Chinese-specific peony seed oil by using confocal Raman spectroscopy and chemometrics. Food Chem. 2021, 362, 130041. [CrossRef] [PubMed]

38. Bresson, S.; Lecuelle, A.; Bougrioua, F.; El Hadri, M.; Baeten, V.; Courty, M.; Pilard, S.; Rigaud, S.; Faivre, V. Comparative structural and vibrational investigations between cocoa butter (CB) and cocoa butter equivalent (CBE) by ESI/MALDI-HRMS, XRD, DSC, MIR and Raman spectroscopy. Food Chem. 2021, 363, 130319. [CrossRef] [PubMed]

39. Castro, R.C.; Ribeiro, D.S.; Santos, J.L.; Páscoa, R.N. Comparison of near infrared spectroscopy and Raman spectroscopy for the identification and quantification through MCR-ALS and PLS of peanut oil adulterants. Talanta 2021, 230, 122373. [CrossRef] [PubMed]

40. Zhang, X.; de Juan, A.; Tauler, R. Multivariate Curve Resolution Applied to Hyperspectral Imaging Analysis of Chocolate Samples. Appl. Spectrosc. 2015, 69, 993-1003. [CrossRef] [PubMed]

41. de Juan, A.; Tauler, R. Multivariate Curve Resolution: 50 years addressing the mixture analysis problem-A review. Anal. Chim. Acta 2021, 1145, 59-78. [CrossRef]

42. Gupta, S.; Román-Ospino, A.D.; Baranwal, Y.; Hausner, D.; Ramachandran, R.; Muzzio, F.J. Performance assessment of linear iterative optimization technology (IOT) for Raman chemical mapping of pharmaceutical tablets. J. Pharm. Biomed. Anal. 2021, 205, 114305. [CrossRef]

43. MCR Constraints-Eigenvector Research Documentation Wiki. Available online: https://www.wiki.eigenvector.com/index. php?title=MCR_Constraints (accessed on 30 October 2021).

44. Firmani, P.; Hugelier, S.; Marini, F.; Ruckebusch, C. MCR-ALS of hyperspectral images with spatio-spectral fuzzy clustering constraint. Chemom. Intell. Lab. Syst. 2018, 179, 85-91. [CrossRef]

45. Gendrin, C. Monitoring galenical process development by near infrared chemical imaging: One case study. Eur. J. Pharm. Biopharm. 2008, 68, 828-837. [CrossRef]

46. Lyon, R.C.; Lester, D.S.; Lewis, E.N.; Lee, E.; Yu, L.X.; Jefferson, E.H.; Hussain, A.S. Near-infrared spectral imaging for quality assurance of pharmaceutical products: Analysis of tablets to assess powder blend homogeneity. AAPS PharmSciTech 2002 , 3, E17. [CrossRef] [PubMed]

47. Wang, K.; Li, Z.; Li, J.; Lin, H. Raman spectroscopic techniques for nondestructive analysis of agri-foods: A state-of-the-art review. Trends Food Sci. Technol. 2021, 118, 490-504. [CrossRef]

48. Metilli, L.; Francis, M.; Povey, M.; Lazidis, A.; Marty-Terrade, S.; Ray, J.; Simone, E. Latest advances in imaging techniques for characterizing soft, multiphasic food materials. Adv. Colloid Interface Sci. 2020, 279, 102154. [CrossRef]

49. Gómez-Mascaraque, L.G.; Tran, C.; O'Callaghan, T.; Hogan, S.A. Use of confocal Raman imaging to understand the microstructure of anhydrous milk fat-based oleogels. Food Struct. 2021, 30, 100228. [CrossRef]

50. Long, Y.; Huang, W.; Wang, Q.; Fan, S.; Tian, X. Integration of textural and spectral features of Raman hyperspectral imaging for quantitative determination of a single maize kernel mildew coupled with chemometrics. Food Chem. 2021, 372, 131246. [CrossRef] [PubMed] 
51. Liu, X.; Ji, Z.; Peng, W.; Chen, M.; Yu, L.; Zhu, F. Chemical mapping analysis of compatibility in gelatin and hydroxypropyl methylcellulose blend films. Food Hydrocoll. 2020, 104, 105734. [CrossRef]

52. Mitsutake, H.; da Silva, G.; Ribeiro, L.; de Paula, E.; Poppi, R.; Rutledge, D.; Breitkreitz, M. Raman Imaging and Chemometrics Evaluation of Natural and Synthetic Beeswaxes as Matrices for Nanostructured Lipid Carriers Development. Braz. J. Anal. Chem. 2021, 8, 116-130. [CrossRef]

53. Huang, Z.; Guo, Z.; Xie, D.; Cao, Z.; Chen, L.; Wang, H.; Jiang, L.; Shen, Q. Rhizomucor miehei lipase-catalysed synthesis of cocoa butter equivalent from palm mid-fraction and stearic acid: Characteristics and feasibility as cocoa butter alternative. Food Chem. 2021, 343, 128407. [CrossRef] 